\title{
Radiographic patterns and associations of osteoarthritis of the knee in patients referred to hospital
}

\author{
Joanna Ledingham, Marian Regan, Adrian Jones, Michael Doherty
}

\begin{abstract}
Objectives-To investigate differing patterns and associations of osteoarthritis of the knee in patients referred to hospital. Methods-Two hundred and fifty two consecutive patients (161 women, 91 men; mean age 70 years, range 34-91 years) referred to hospital with osteoarthritis of the knee underwent clinical, radiographic, and synovial fluid screening.

Results-Radiographic changes of osteoarthritis of the knee (definite narrowing with or without osteoarthritic features) were bilateral in $85 \%$ of patients. Of 470 knees affected, $277(59 \%)$ were affected in two compartments and $28(6 \%)$ in three compartments. Unilateral and isolated medial tibiofemoral osteoarthritis were more common in men. Calcium pyrophosphate crystal deposition was common (synovial fluid identification in $132(28 \%)$ knees; knee chondrocalcinosis in $76(30 \%)$ patients) and associated with disability, bilateral, multicompartmental and severe radiographic osteoarthritis, marked osteophytosis, attrition, and cysts. Multiple clinical nodes (58 (23\%) patients) and radiographic polyarticular interphalangeal osteoarthritis (66 (26\%) patients) were associated with a higher frequency of inactivity pain, disability, multicompartmental and severe radiographic change. Forestier's disease predominated in men but showed no other associations.
\end{abstract}

Conclusions-In a group of patients referred to hospital osteoarthritis of the knee is usually bilateral and affects more than one compartment. Severe and multicompartmental radiographic changes are associated with calcium pyrophosphate crystal deposition, nodal change, and polyarticular interphalangeal osteoarthritis.

(Ann Rheum Dis 1993; 52: 520-526)

Osteoarthritis comprises $20 \%$ of a rheumatologist's workload, with the knee the most common joint affected. ${ }^{12}$ A variety of subclassifications of osteoarthritis of the knee have been proposed, mainly according to radiographic patterns of compartmental disease ${ }^{3-8}$ the presence and extent of individual radiographic features, and the presence of associated calcium pyrophosphate $e^{8-13}$ or basic calcium phosphate (mainly hydroxyapatite ${ }^{13}$ ) crystal deposition. Furthermore, osteoarthritis of the knee occurring in isolation may differ from that occurring in combination with other large and small joint involvement; isolated osteoarthritis of the knee is reportedly more common in men ${ }^{6}$ and after local trauma or menisectomy. ${ }^{14}{ }^{15}$ Patients with Heberden's or Bouchard's nodes, or both, may represent a distinct 'subset' with a possible systemic aetiology (nodal generalised osteoarthritis ${ }^{16}$ ). This is supported by multifocal disease, a reported association with axial migration of the femoral head (the pattern that occurs in inflammatory arthropathies ${ }^{17}{ }^{18}$ ), an increased frequency of class specific rheumatoid factor, ${ }^{19}$ and a predisposition to more common and severe 'secondary' osteoarthritis after miniscectomy. ${ }^{20} \mathrm{~A}$ recent study of osteoarthritis of the hip, however, has questioned the existence of such a discrete 'subset'. ${ }^{21}$

The aim of this study was to investigate such possible associations with osteoarthritis of the knee in a large group of patients referred to hospital, taking into account differential compartmental disease of the knee. Particular interest focused on calcium crystal deposition, and hand and multiple joint involvement.

\section{Patients and methods}

This study was approved by the local ethical committee. Consecutive patients referred to a single general rheumatology clinic with symptomatic osteoarthritis of the knee as their primary reason for referral were recruited over a two year period.

DIAGNOSTIC CRITERIA

Osteoarthritis of the knee was defined radiographically by the presence of joint space narrowing with osteophyte or cyst formation, sclerosis, or attrition. Other arthropathies were excluded by clinical examination, laboratory investigations (including erythrocyte sedimentation rate, serum calcium, and rheumatoid factor by the latex and RoseWaaler tests (titre $<1 / 64$ ), and the absence of marginal erosions, sacroiliitis, and isolated osteonecrosis on radiographic screening. 
ASSESSMENTS

Historical

A full rheumatological history and examination was obtained for each patient, with particular emphasis on the presence of activity, rest and nocturnal knee pain (each graded 0-3), reported duration of symptoms, and past history of previous major trauma or operations (including meniscectomy) to the knees. Disability was estimated using the Steinbrocker index ${ }^{22}$ and the body mass index (weight/height ${ }^{2}$ ) documented. Multiple interventions (for example, various non-steroidal anti-inflammatory drugs (NSAIDs), intraarticular injections, advice on exercise and diet) had often been used before entry to the study, making analysis of individual interventions impossible.

\section{Clinical}

On examination, clinical abnormalities consistent with osteoarthritis (crepitus, reduced movement, bony change) were noted for all non-axial joints. Nodal change was defined clinically as the presence of typical superolateral Heberden's or Bouchard's nodes, or both, affecting at least three rays of each hand. Knees were assessed for the presence of effusions in addition to other signs of osteoarthritis (joint line tenderness, crepitus, temperature change, and range of movement).

\section{Synovial fluid}

Knee joint aspiration was undertaken on all affected knees, even in the absence of clinical effusion, to exclude gout and to determine the presence of associated calcium pyrophosphate crystal deposition (compensated polarised light microscopy) and other calcium containing particles (alizarin red staining at acid $\mathrm{pH}^{23}$ ).

\section{Radiographic}

Plain radiographs were taken of the knees (standing anteroposterior plus $20^{\circ}$ flexion lateral views), pelvis (supine anteroposterior), hands (to include wrists), shoulders, lumbar spine (anteroposterior and lateral), and thoracic spine (anteroposterior) of each patient, together with any other clinically affected joint. After an initial training period all study radiographs were graded by a single pair of observers. A global grading system, centred around joint space narrowing, was used to assess the radiographic 'severity' at all joints: mild change was defined by definite narrowing with osteophyte/sclerosis (equivalent to Kellgren grade $2^{24}$ ); moderate change as marked narrowing with osteophyte/sclerosis; and severe change as obliteration of the joint space. Overall severity was assessed separately for each knee compartment (medial tibiofemoral, lateral tibiofemoral and patellofemoral). Multiple large joint disorders were defined as at least one other large joint (hip, shoulder) being affected in addition to the knee, and polyarticular interphalangeal osteoarthritis was defined by radiographic evidence of arthritis of at least three rays of both hands. Chondrocalcinosis and Forestier's disease ${ }^{25}$ were recorded if present.

In addition, for each knee compartment, individual radiographic features (joint space narrowing, osteophytosis, cyst formation, sclerosis, and attrition) were each graded 0-3 using a modification of the method of Thomas et al. ${ }^{8}$ The pattern of bone response, originally described in osteoarthritis of the hip (atrophic, hypertrophic, or intermediate ${ }^{26}$ ), was also determined for each knee.

\section{STATISTICAL ANALYSIS}

Intraobserver variability for the two observers was assessed by the blind rescoring of 50 complete sets of radiographs on completion of the study and using the $\kappa$ statistic. ${ }^{27}$ Other statistical analyses were performed using the $\chi^{2}$ and Fisher's tests as appropriate. Odds ratios were calculated with respect to the presence or absence of putative associated factors; continuous variables were assessed using logistic regression and stepwise logistic regression was used for multivariate analysis (Egret, Serc, Seattle). Patient characteristics such as age, sex, body mass index, presence of nodal change, polyarticular interphalangeal osteoarthritis, and chondrocalcinosis, together with any factors found to be associated on univariate analysis were included in the models.

\section{Results}

Two hundred and fifty two patients were recruited into the study (table 1 ). They were predominantly women, obese and elderly and had had knee symptoms for a long period before referral to hospital.

Clinical nodal change and radiographic polyarticular interphalangeal osteoarthritis were more common in women (odds ratios $5 \cdot 29$ and $3 \cdot 53,95 \%$ confidence intervals (CIs) $2 \cdot 76$ to $10 \cdot 3$ and $2 \cdot 05$ to $6 \cdot 13$ respectively). Radiographic interphalangeal osteoarthritis was more common in elderly patients (odds ratio $3 \cdot 29,95 \%$ CI 1.93 to $5 \cdot 61$ ).

Chondrocalcinosis occurred with increased frequency with increasing age (odds ratio 1.06, $95 \%$ CI 1.04 to 1.09 ). Synovial fluid was obtained from $80 \%$ of affected knees, allowing the identification of calcium pyrophosphate crystals in $28 \%$ of aspirated knees and in $9 \%$ of knees without chondrocalcinosis. Forestier's disease $^{25}$ and changes typical of Forestier's disease but not fulfilling the criteria were more common in men (odds ratios 3.23 and 3.13 , $95 \%$ CIs 1.08 to 10.0 and 1.67 to 5.88 respectively).

Two hundred and fourteen (85\%) patients had bilateral knee osteoarthritis and two patients presented with their second knee affected after previous knee replacement. A total of 470 osteoarthritic knees were therefore assessed. Only $29 \quad(6 \%)$ radiographically affected knees were asymptomatic, whereas 19 $(56 \%)$ of the 34 radiographically normal knees were symptomatic. Patellofemoral and 
Table 1 Characteristics of the 252 patients studied. Values are No (\%)

\begin{tabular}{|c|c|c|}
\hline & $\begin{array}{l}\text { Women } \\
(n=161)\end{array}$ & $\begin{array}{l}M e n \\
(n=91)\end{array}$ \\
\hline $\begin{array}{l}\text { Median (range; interquartile range) (years) } \\
\text { Median (range; interquartile rate) symptom duration (years) } \\
\text { Median (range; interquartile range) body mass indix }\end{array}$ & $\begin{array}{l}73(38-91 ; 65-77) \\
8 \cdot 75(1-52 ; 5-15) \\
28 \cdot 2(19 \cdot 3-42 \cdot 4 ; 25 \cdot 0-32 \cdot 7)\end{array}$ & $\begin{array}{l}65(34-87 ; 61-75) \\
8 \cdot 5(1-52 ; 6-15) \\
27 \cdot 7(17 \cdot 5-40 \cdot 7 ; 25 \cdot 0-30 \cdot 4)\end{array}$ \\
\hline $\begin{array}{l}\text { Osteoarthritis of the knee } \\
\text { Unilateral } \\
\text { Bilateral } \\
\text { Previous TKR }\end{array}$ & $\begin{array}{l}17(11) \\
144(89) \\
1(1)\end{array}$ & $\begin{array}{c}18(19) \\
72(80) \\
1(1)\end{array}$ \\
\hline Isolated osteoarthritis of the knee & $27(17)$ & $29(32)$ \\
\hline $\begin{array}{l}\text { Radiographic osteoarthritis at other sites } \\
\text { Polyarticular interphalangeal } \\
\text { Any interphalangeal } \\
\text { First carpometacarpal } \\
\text { Hand } \\
\text { Hip } \\
\text { Glenohumeral }\end{array}$ & $\begin{array}{r}55(34) \\
106(66) \\
84(52) \\
131(81) \\
22(14) \\
24(15)\end{array}$ & $\begin{array}{l}11(12) \\
42(46) \\
26(29) \\
55(60) \\
12(13) \\
6(7)\end{array}$ \\
\hline Nodal changes & $50(30)$ & $6(7)$ \\
\hline Chondrocalcinosis & $51(31)$ & $32(35)$ \\
\hline Forestier's disease & $3(2)$ & $7(8)$ \\
\hline
\end{tabular}

tibiofemoral osteoarthritis were bilateral in 189 $(75 \%)$ and $141(56 \%)$ patients respectively. Bicompartmental osteoarthritis occurred most commonly and tricompartmental disease was unusual. Unicompartmental disease most commonly occurred in the patellofemoral $(68 \%)$ and least commonly in the lateral tibiofemoral ( $2 \%$ ) compartment (figure).

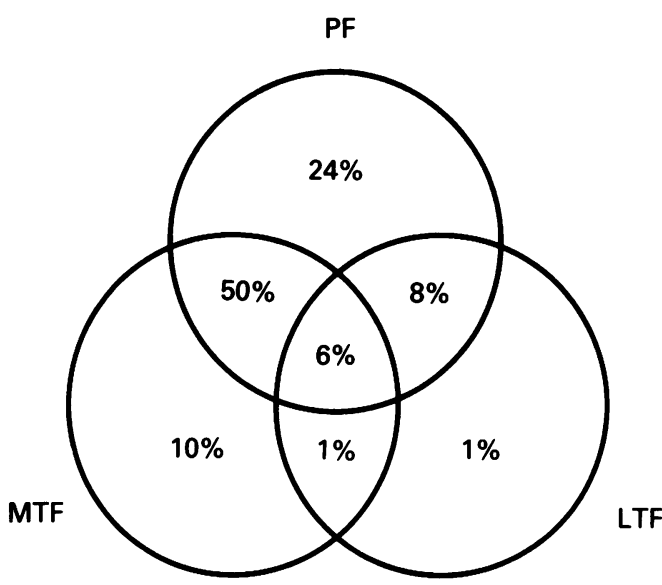

Venn diagram showing patterns of compartmental disease in osteoarthritis of the knee. $P F=$ Patellofemoral; $M T F=$ medial tibiofemoral; and LTF=lateral tibiofemoral.
Symmetrical compartmental involvement was seen in patients with bilateral disease $(p<0.001)$. A hypertrophic pattern of bone response was seen in 207 (44\%) knees; an atrophic pattern occurred in $89(19 \%)$ and a mixed pattern was seen in $174(37 \%)$. Osteophyte was present in $470(100 \%)$, sclerosis in $362(77 \%)$, cysts in $249(53 \%)$, and attrition in $136(29 \%)$ knees.

\section{ASSOCIATIONS}

Factors associated (on univariate analysis) with a variety of clinical and radiographic features are shown in tables 2 and 3 and were entered into the logistic regression models for multivariate analysis together with the factors described under methods.

\section{Multivariate analysis}

An increased frequency of bilateral, multicompartmental and severe osteoarthritis, attrition, atrophic bone response, and functional impairment (Steinbrocker grades 3 and 4) occurred with increasing age at the time of hospital referral (tables 4 and 5). Younger patients more commonly had a history of trauma.

Table 2 Odds ratios and confidence intervals for selected symptoms, clinical signs, and disablility in patients with osteoarthritis of the knee. Univariate analysis

\begin{tabular}{|c|c|c|c|}
\hline & & Odds ratio & $95 \%$ Confidence interval \\
\hline \multicolumn{4}{|l|}{ Symptoms } \\
\hline \multirow[t]{3}{*}{ Rest Pain } & Nodal change & 1.96 & $1 \cdot 22$ to $3 \cdot 14$ \\
\hline & Attrition & $1 \cdot 82$ & $1 \cdot 17$ to $2 \cdot 83$ \\
\hline & Polyarticular interphalangeal osteoarthritis & $1 \cdot 82$ & 1.09 to $2 \cdot 70$ \\
\hline \multirow{2}{*}{ Nocturnal pain } & Attrition & $1 \cdot 71$ & $1 \cdot 11$ to $2 \cdot 64$ \\
\hline & Knee effusion & 1.56 & 0.99 to 2.46 \\
\hline \multicolumn{4}{|l|}{ Past History } \\
\hline \multirow[t]{2}{*}{ Meniscectomy } & Male & $20 \cdot 8$ & $4 \cdot 62$ to 130 \\
\hline & Younger age (continuous variable) & $1 \cdot 06$ & 1.02 to 1.11 \\
\hline \multirow{2}{*}{ Trauma } & Younger age (continuous variable) & $1 \cdot 08$ & 1.04 to 1.11 \\
\hline & Male & $3 \cdot 02$ & 1.42 to 6.48 \\
\hline \multirow[t]{6}{*}{ Disability } & Older age ( $>80$ years) & $11 \cdot 2$ & 6.17 to 20.4 \\
\hline & CPPD & 2.56 & 1.42 to 4.59 \\
\hline & Nodal change & $2 \cdot 82$ & 1.63 to 4.87 \\
\hline & Polyarticular interphalangeal osteoarthritis & $5 \cdot 08$ & 2.96 to 8.72 \\
\hline & Female sex & 3.59 & $1 \cdot 81$ to $7 \cdot 25$ \\
\hline & Chondrocalcinosis & $1 \cdot 76$ & 1.05 to 2.96 \\
\hline \multicolumn{4}{|l|}{ Clinical signs } \\
\hline Varus & Male & 1.89 & 1.22 to 2.86 \\
\hline Knee effusion & Male & 1.92 & $1 \cdot 20$ to 3.13 \\
\hline
\end{tabular}


Table 3 Odds ratios and confidence intervals for radiographic features at the knee: univariate analysis

\begin{tabular}{|c|c|c|c|}
\hline & & Odds ratio & $95 \%$ Confidence interval \\
\hline \multicolumn{4}{|l|}{ Severe osteoarthritis } \\
\hline \multirow[t]{2}{*}{ Patellofemoral } & Female & 3.69 & $2 \cdot 10$ to $6 \cdot 54$ \\
\hline & Chondrocalcinosis & 1.66 & 1.06 to 2.61 \\
\hline \multirow[t]{3}{*}{ Medial tibiofemoral } & Older age $(>80$ years $)$ & 2.52 & 1.45 to 4.36 \\
\hline & CPPD & 3.37 & 2.00 to 5.69 \\
\hline & Male & 1.85 & 1.16 to 2.94 \\
\hline \multirow[t]{3}{*}{ Lateral tibiofemoral } & Older age ( $>80$ years) & $6 \cdot 29$ & 1.99 to 20.0 \\
\hline & CPPD & $7 \cdot 23$ & 1.70 to $35 \cdot 2$ \\
\hline & Nodal change & 3.07 & 0.97 to 9.58 \\
\hline \multirow[t]{4}{*}{ Bilateral osteoarthritis } & Older age ( $>80$ years) & $7 \cdot 67$ & 6.65 to 8.85 \\
\hline & Chondrocalcinosis & $2 \cdot 81$ & 1.08 to 7.69 \\
\hline & Female & $2 \cdot 20$ & 1.06 to 4.60 \\
\hline & Obesity (body mass index $>30$ ) & $2 \cdot 54$ & 0.97 to 7.07 \\
\hline \multirow[t]{4}{*}{ Multicompartmental osteoarthritis } & Older age ( $>80$ years) & $2 \cdot 84$ & 1.49 to 5.50 \\
\hline & CPPD & 2.59 & 1.44 to $4 \cdot 70$ \\
\hline & Nodal change & 2.99 & 1.69 to 5.33 \\
\hline & Polyarticular interphalangeal osteoarthritis & 2.78 & 1.65 to 4.71 \\
\hline Isolated medial tibiofemoral & Male & 2.01 & 1.03 to 3.90 \\
\hline \multicolumn{4}{|l|}{ Bone response pattern } \\
\hline \multirow[t]{2}{*}{ Atrophic } & Older age ( $>80$ years) & 3.46 & 1.96 to 6.09 \\
\hline & Knee effusion ( $>5 \mathrm{ml}$ aspirated) & 1.86 & 1.13 to 3.05 \\
\hline Hypertrophic & Younger age ( $<60$ years) & 1.69 & 0.97 to 2.94 \\
\hline
\end{tabular}

Women more often had severe patellofemoral disease, an older age of symptom onset, and more associated disability. Men more often had isolated medial tibiofemoral osteoarthritis, clinical knee effusions, and a history of trauma and meniscectomy.

Chondrocalcinosis was associated with multicompartmental disease and increased disease severity. Calcium pyrophosphate dihydrate crystals showed the same associations as chondrocalcinosis, occurred with increased frequency in knees with severe radiographic changes and, in particular, in knees with marked attrition, sclerosis, and cystic change (odds ratios 1.92, 1.73, and 1.34; $95 \%$ CIs $1 \cdot 53$ to $2 \cdot 45,1 \cdot 41$ to $2 \cdot 12$, and $1 \cdot 14$ to 1.57 respectively). Isolated patellofemoral osteoarthritis was not found to be more common in association with chondrocalcinosis or calcium pyrophosphate crystals.

Patients with chondrocalcinosis and calcium pyrophosphate crystal deposition were older, more disabled, and more commonly had nodal change and polyarticular interphalangeal osteoarthritis (all $\mathrm{p}<0.03$ ); no associations were found with gender or with bone response

Table 4 Odds ratios and confidence intervals for selected symptoms, clinical signs, and disability in patients with osteoarthritis of the knee: multivariate analysis. Age and body mass index were analysed as continuous variables

\begin{tabular}{|c|c|c|c|}
\hline & & Odds ratio & $95 \%$ Confidence interval \\
\hline $\begin{array}{l}\text { Symptoms } \\
\text { Rest pain } \\
\text { Nocturnal pain }\end{array}$ & $\begin{array}{l}\text { Attrition } \\
\text { Nodal change } \\
\text { Attrition } \\
\text { Knee effusion (>5 ml aspirated) } \\
\text { Body mass index }\end{array}$ & $\begin{array}{l}1 \cdot 93 \\
1 \cdot 87 \\
1 \cdot 80 \\
1 \cdot 02 \\
1 \cdot 10\end{array}$ & $\begin{array}{l}1.20 \text { to } 3.11 \\
1.13 \text { to } 3.11 \\
1.10 \text { to } 2.96 \\
1.01 \text { to } 1.04 \\
1.04 \text { to } 1.16\end{array}$ \\
\hline $\begin{array}{l}\text { Past history } \\
\text { Meniscectomy } \\
\text { Trauma }\end{array}$ & $\begin{array}{l}\text { Male } \\
\text { Younger age } \\
\text { Male }\end{array}$ & $\begin{array}{c}20 \cdot 8 \\
1 \cdot 07 \\
2 \cdot 33\end{array}$ & $\begin{array}{l}4.08 \text { to } 90 \cdot 3 \\
1.04 \text { to } 1 \cdot 11 \\
1.13 \text { to } 4.83\end{array}$ \\
\hline Disability & $\begin{array}{l}\text { Female } \\
\text { Polyarticular interphalangeal osteoarthritis } \\
\text { Older age }\end{array}$ & $\begin{array}{l}2 \cdot 22 \\
2 \cdot 06 \\
1 \cdot 16\end{array}$ & $\begin{array}{l}1.01 \text { to } 4.87 \\
1.07 \text { to } 3.98 \\
1.10 \text { to } 1.23\end{array}$ \\
\hline $\begin{array}{l}\text { Clinical signs } \\
\text { Knee effusion }\end{array}$ & Male & $1 \cdot 79$ & 1.35 to 2.38 \\
\hline
\end{tabular}

Table 5 Odds ratios and confidence intervals for radiographic features at the knee: multivariate analysis. Age and body mass index were analysed as continuous variables

\begin{tabular}{|c|c|c|c|}
\hline & & Odds ratio & 95\% Confidence interval \\
\hline \multicolumn{4}{|l|}{ Severe osteoarthritis } \\
\hline \multirow[t]{2}{*}{ Patellofemoral } & Female & $3 \cdot 50$ & 2.01 to 6.06 \\
\hline & Body mass index & 0.95 & 0.92 to 0.95 \\
\hline \multirow[t]{4}{*}{ Medial tibiofemoral } & $\mathrm{CPPD}^{\star}$ & $6 \cdot 19$ & 3.03 to 12.6 \\
\hline & Male & 2.94 & 1.61 to 5.00 \\
\hline & Body mass index & $1 \cdot 11$ & 1.04 to 1.18 \\
\hline & Older age & 1.05 & 1.02 to 1.09 \\
\hline \multirow{2}{*}{ Lateral tibiofemoral } & CPPD & 7.07 & 1.41 to $35 \cdot 4$ \\
\hline & Polyarticular interphalangeal osteoarthritis & $6 \cdot 39$ & $1 \cdot 27$ to $32 \cdot 0$ \\
\hline \multirow{2}{*}{ Bilateral osteoarthritis } & Older age & $1 \cdot 15$ & 1.09 to 1.22 \\
\hline & Body mass index & $1 \cdot 13$ & 1.01 to 1.26 \\
\hline \multirow[t]{4}{*}{ Multicompartmental osteoarthritis } & CPPD & $3 \cdot 31$ & 1.61 to 6.77 \\
\hline & Nodal change & $2 \cdot 43$ & 1.25 to 4.73 \\
\hline & Body mass index & $1 \cdot 12$ & 1.06 to 1.19 \\
\hline & Older age & 1.05 & 1.02 to 1.08 \\
\hline \multicolumn{4}{|l|}{ Bone response pattern } \\
\hline \multirow[t]{2}{*}{ Atrophic } & Knee effusion ( $>5 \mathrm{ml}$ aspirated) & $2 \cdot 24$ & $1 \cdot 25$ to $4 \cdot 04$ \\
\hline & Older age & 1.05 & 1.02 to 1.09 \\
\hline Hypertrophic & No knee effusion & 1.43 & 1.04 to 2.00 \\
\hline
\end{tabular}


Table 6 Kappa values for the knee joint

\begin{tabular}{lll}
\hline & Kappa value & $95 \%$ Confidence interval \\
\hline Patellofemoral Kellgren grade & 0.65 & 0.53 to 0.77 \\
Medial tibiofemoral Kellgren grade & 0.85 & 0.76 to 0.94 \\
Lateral tibiofemoral Kellgren grade & 0.87 & 0.74 to 0.99 \\
Bone response pattern & 0.48 & 0.34 to 0.52 \\
Osteophyte score & 0.75 & 0.63 to 0.77 \\
Cyst score & 0.47 & 0.31 to 0.63 \\
Sclerosis score & 0.73 & 0.57 to 0.89 \\
Attrition score & 0.64 & 0.48 to 0.80 \\
\hline
\end{tabular}

patterns, and synovial fluid alizarin red positivity showed associations only with the presence of clinically detectable knee effusions. The atrophic bone response occurred more often in knees with clinical effusions and from which at least $5 \mathrm{ml}$ of fluid was aspirated.

Polyarticular interphalangeal osteoarthritis and nodal change were more common in patients with bicompartmental and tricompartmental disease, severe lateral tibiofemoral disease, prominent osteophytosis (odds ratio $1 \cdot 16,95 \%$ CI 1.05 to $1 \cdot 28$ ), an older age of symptom onset (odds ratio $1 \cdot 11,95 \%$ CI 1.08 to $1 \cdot 14$ ), rest pain, and more disability. No association, except patient gender, was found with Forestier's disease.

Total pain scores were higher in association with severe radiographic scores for osteoarthritis, multicompartmental disease, attrition, nodal change, and marked disability (all $p<0.03$ ). Inactivity pain was more common in patients with nodal change, knee effusions, and in association with attrition. No gender difference was found with regard to symptoms.

Obesity was found to associate with bilaterality and severe tibiofemoral and multicompartmental disease.

\section{Reproducibility}

Intraobserver reproducibility for radiographic assessments was good for the knee (table 6) and for the peripheral joints (range 0.46 for the wrist to 0.83 for the shoulder). Assessments for the patellofemoral compartment were less reproducible than for the other compartments and the pattern of bone response was only moderately reproducible.

\section{Discussion}

This large survey supports some of the findings from previous studies and suggests other associations that have not been reported. Although factors that associate with the development of osteoarthritis may best be determined by community based studies, hospital based surveys may contribute information on factors that are associated with severity. All patients in this study had symptomatic osteoarthritis of the knee sufficiently severe to warrant referral to hospital. A large number of consecutive patients were included, but our results and conclusions are clearly restricted to symptomatic knees and the more severe end of the spectrum of structural change.

With regard to symptoms, it was of interest that reported rest and night pain were associated with radiographic attrition and that effusions were associated with night pain. A cross sectional survey of patients with osteoarthritis of the hip similarly found an association between attrition and night pain. ${ }^{21}$ These findings support the view that different mechanisms of pain production may result in different clinical patterns of pain in osteoarthritis. $^{28}$ Subchondral microfracture and intraosseous hypertension might be expected to be the principal mechanisms of pain in subjects with marked attrition, whereas intracapsular distension might cause pain in those with effusions. Furthermore, the concurrence of attrition and effusions could be used as evidence to support the theory of a secondary 'debris synovitis' occurring in severely damaged osteoarthritic joints.

In accord with one other study, ${ }^{6}$ osteoarthritis of the knee was most commonly bilateral, bicompartmental, and symmetrical. There were clear differences between the sexes. Women showed greater disablility and were more likely to have bilateral, multicompartmental and polyarticular disease, nodal change, and greater radiographic severity, particularly at the patellofemoral joint. Men, by comparison, had a younger age at onset and more often had unilateral osteoarthritis of the knee, a past history of meniscectomy or trauma, varus deformity, and isolated medial compartment disease (even after correcting for previous meniscectomy). That women have the greater functional disability and pain has previously been reported. ${ }^{29}$ In our study many associations remained after accounting for older age and higher frequency of polyarticular osteoarthritis in women, suggesting that women have a more severe form of osteoarthritis of the knee. Different disease mechanisms may thus exist according to patient gender, with men being more likely to develop localised 'secondary' osteoarthritis of the knee, and women being more susceptible to a 'primary', multifocal form of osteoarthritis affecting the knee, often characterised by the presence of nodal change. Certainly this study supports the concept of 'generalised' predisposition to osteoarthritis in some patients.

As with all osteoarthritis studies there are inherent problems associated with assessment by plain radiographs. For example, the low frequency of coexistent medial and lateral tibiofemoral osteoarthritis may be an underestimate of the true prevalence owing to the requirement of definite joint space narrowing for radiographic diagnosis of osteoarthritis. Although radiographs of weightbearing joints are superior to supine films for the detection of joint space narrowing, ${ }^{83031}$ problems still arise owing to radiographic widening in the adjacent less severely affected compartment. ${ }^{8}$ In this study the patellofemoral compartment was included in the radiographic assessment and was found to be the single most common compartment affected. This finding agrees with another reported survey, ${ }^{32}$ and has implications with respect to the interpretation of previous studies where this compartment 
has often been omitted. Assessment of the patellofemoral joint using lateral radiographs is not without its problems, however, with poorer reproducibility of assessments compared with that obtained for the tibiofemoral compartments.

As reported for osteoarthritis of the hip, ${ }^{21}$ older age at presentation is associated with more attrition and atrophic bone response at the knee. In addition, patients with a late presentation showed more multicompartmental knee disease and higher Kellgren scores. Although dependent on patient reporting, the duration of symptoms appeared the same in old and young subjects, suggesting that older subjects have less ability to mount a hypertrophic bone response in osteoarthritis. This same suggestion arose in a study of patients with osteoarthritis of the hip referred to hospital ${ }^{21}$ and accords with reports of severe atrophic, rapidly progressive osteoarthritis which is almost confined to elderly women. ${ }^{33}$ A potential confounding factor, however, is later presentation and greater severity in women. Whether the tendency to an atrophic response relates to factors associated with aging itself, gender differences, or both, remains to be determined.

This is the first study systematically to examine synovial fluid of the knee in a high proportion of patients. Aspiration was attempted on all osteoarthritic knees and sufficient fluid for microscopy was obtained in $376(80 \%)$. Calcium pyrophosphate crystal deposition (confirmed by synovial fluid or assumed from radiographic chondrocalcinosis) associated with severe, multicompartmental osteoarthritis and, in particular, with cystic change, sclerosis and attrition. Previous studies have reported similar associated patterns of change ${ }^{8-13}$ : in contrast with other studies, however, no associatoin was found with isolated patellofemoral disease. This finding concurs with a study of a broad spectrum of symptomatic and asymptomatic osteoarthritic knees, which also found calcium pyrophosphate crystals to associate with extensive, severe osteoarthritis rather than particular patterns of compartmental disease. ${ }^{34}$ No radiographic associations were found with alizarin red positivity, a relatively specific test (at acidic $\mathrm{pH}$ ) for apatite,$^{23}$ though one previous survey including asymptomatic osteoarthritic knees found similar associations with those of calcium pyrophosphate crystals. It remains possible that the relative concentrations of calcium particles in the synovial fluid of patients with osteoarthritis may be more relevant than simply their presence or absence, though accurate methods of quantifying synovial fluid particles have yet to be devised. Interestingly, the presence of alizarin red positivity did associate with 'significant' effusions and this could support the postulated role of calcific particles in 'secondary synovitis' in osteoarthritis.

The finding that nodal change and polyarticular interphalangeal osteoarthritis associated with multiple joint disease, multiple compartment disease at the knee, radiographic severity (particularly lateral compartment), and more rest pain and disability agrees with previous reports ${ }^{20}$ and provides further support for the concept of a 'subgroup' with nodal generalised osteoarthritis. These associations were not seen with pauciarticular osteoarthritis and were independent of gender differences. Although the definition of nodal generalised osteoarthritis is still uncertain, this study supports the presence in some subjects of a constitutional, systemic predisposition to polyarticular and extensive osteoarthritis, with hand disease as the marker for this predisposition. That osteoarthritis is a heterogeneous disorder, determined and affected by a variety of systemic and local factors, has previously been emphasised. ${ }^{35}$ Interestingly, obesity is associated with bilaterality, severity and multicompartmental disease in osteoarthritis of the knee; this could support either constitutional predisposition (hormonal or metabolic ${ }^{36}$ ), or the influence of local mechanical factors, or both.

We are grateful to Roussel Laboratories UK Ltd and Trent Regional Health Authority for financial support.

1 Bohan A. The private practice of rheumatology. Arthritis Rheum 1981; 24: 1304-7.

2 Mazanec D J. First years of a rheumatologist in private practice. Arthritis Rheum 1982; 25: 718-9.

3 Ahlbach S. Osteoarthritis of the knee - a radiographic investigation. Acta Radiol 1968; 277: 6-71.

4 Kannus B, Jarvinen M, Salminon E, et al. Occurrence of symptomatic knee osteoarthritis in rural Finland: a prospective follow-up study. Ann Rheum Dis 1987; 46: 804-8.

5 Schouten J S A G, van den Ouweland F A, Valkenburg H A. A 12 year follow-up study on osteoarthritis of the kne in the general population on prognostic factors of cartilage loss in osteoarthritis of the knee. Ann Rheum Dis 1992; 51: $932-7$

6 Cushnaghan J, Dieppe P. Study of 500 patients with limb joint osteoarthritis 1. Analysis by age, sex and distribution of symptomatic joint sites. Ann Rheum Dis 1991; 50: $8-13$.

7 Hernborg J S, Nilsson B E. The natural course of untreated osteoarthritis of the knee. Clin Orthop 1977; 123: 130-7.

8 Thomas R H, Resnick D, Alazraki N P, Davies D Greenfield R. Compartmental evaluation of osteoarthritis of the knee. A comparative study of available diagnostic modalities. Diagnostic Radiology 1975; 16: 585-94.

9 Peyron J G. Epidemiological and aetiologic approach of osteoarthritis. Semin Arthritis Rheum 1979; 8: 288-306.

10 Resnick D, Niwayama G, Goergen T G, et al. Clinica radiographic and pathologic abnormalities in calcium pyrophosphate dihydrate deposition disease (CPPD): pyrophosphate dihydrate deposition
pseudogout. Radiology $1977 ; 122: 1-15$.

11 Gorden T P, McCredie M, Smith M, Brooks P M, Ebert B. Articular chondrocalcinosis in a hospital population an Australian experience. Aust $N Z \mathcal{F}$ Med 1984; 14: 655-9.

12 Doherty $M$, Dieppe $P$ A. Clinical aspects of calcium pyrophosphate dihydrate crystal deposition. Rheum Dis Clin North Am 1988; 14: 395-414

13 Halverson P, McCarty D J. Patterns of radiographic abnormalities associated with basic calcium phosphate and calcium pyrophosphate dihydrate deposition in the knee. Ann Rheum Dis 1986; 45: 603-5.

14 Felson D. The epidemiology of knee osteoarthritis: results from the Framingham study. Semin Arthritis Rheum 1990; 20: $42-50$

15 Davis M A. The association of knee injury and obesity with unilateral and bilateral osteoarthritis of the knee. $A m \mathcal{F}$ Epidemiol 1989; 130: 278-88.

16 Kellgren J H, Moore R. Generalised osteoarthritis and Heberdens nodes. $B M F$ 1 $^{2}$ 1952; 1: 180-7.

17 Marks J S, Stewart I M, Hardinge K. Primary osteoarthritis of the hip and Heberden's nodes. Ann Rheum Dis 1979; 38: $107-11$.

18 McGoldrick F, O'Brien T M. Osteoarthritis of the hip and Heberden's nodes. Ann Rheum Dis 1989; 48: 53-5.

19 Hopkinson N, Powell R J, Doherty M. Autoantibodies, immunoglobulins and $\mathrm{Gm}$ allotypes in nodal generalised osteoarthritis. Br f Rheumatol 1992; 31: 605-8.

20 Doherty $M$, Watt I, Dieppe P A. Influence of primary generalised osteoarthritis on development of secondary osteoarthritis. Lancet 1983; 2: 8-11.

21 Ledingham J M, Dawson S, Preston B, Milligan G, Doherty M. osteoarthritis. Ann Rheum Dis 1992; 51: 1111-6. 
22 Steinbrocker O, Traeger C H, Battman R C. Therapeutic criteria for rheumatoid arthritis. $\mathcal{F} A M A$ 1949; 140: 659-62.

23 Putchler H, Meloan S N, Terry M S. On the history and mechanism of alizarin red $\mathrm{S}$ stain for calcium. $\mathcal{F}$ Histochem Cytochem 1969; 17: 110-24.

24 Kellgren J H, Lawrence J S. Radiological assessment of osteoarthritis. Ann Rheum Dis 1957; 16: 494-502.

25 Resnick D, Niwayama G. Diffuse idiopathic skeletal hyperostosis (DISH): ankylosing hyperostosis of Forestier and Rotes-Querol. In: Resnick D, Niwayama G, eds. Diagnosis of bone and joint disorders. Vol 2. Philadelphia: Diagnosis of bone and joint

26 Solomon L. Patterns of osteoarthritis of the hip. $f$ Bone foint Surg $[B r]$ 1976; 58: $176-83$.

27 Cohen J. A coefficient of agreement for nominal scales. Education and Psychological Measurement 1960; 20 37-46.

28 Moskowitz R W. Osteoarthritis - symptoms and signs. In Moskowitz R W, Howell D S, Goldberg V M, Mankin H $\mathrm{J}$, eds. Osteoarthritis: diagnosis and medical/surgical managment. Philadelphia: Saunders, 1992: 255-62.
29 Forman M D, Malamet R, Kaplan D. A survey of osteoarthritis of the knee in the elderly. 7 Rheumatol 1983 10: $282-7$.

30 Gibson P H, Goodfellow J W. Stress radiography in degenerative arthritis of the knee. $\mathcal{F}$ Bone foint Surg $[\mathrm{Br}]$ 1986; 68: 608-9.

31 Leach R E, Gregg T, Siber F J. Weight bearing radiography in osteoarthritis of the knee. Radiology 1970; 97: 265-8.

32 McAlindon $T$ E, Snow S, Cooper C, Dieppe $P$. Radiographic patterns of osteoarthritis of the knee joint in the community: the importance of the patellofemoral joint. Ann Rheum Dis 1992; 51: 844-9.

33 Dieppe P A, Doherty M, MacFarlane D G, Hutton C W, Bradfield J W, Watt I. Apatite associated destructive arthritis. Br F Rheumatol 1984; 23: 84-91.

34 Pattrick M, Hamilton E, Wilson R, Austin S, Doherty M. Association of radiographic changes of osteoarthritis, symptoms and synovial fluid particles in 300 knees. Ann Rheum Dis 1993; 52: 97-103.

35 McAlindon T, Dieppe P. Osteoarthritis: definitions and criteria. Ann Rheum Dis 1989; 48: 531-2.

36 Spector T. The fat of the joint: osteoarthritis and obesity. f Rheumatol 1990; 17: 283-4.

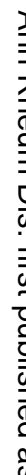

○

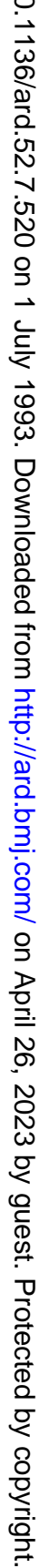

